
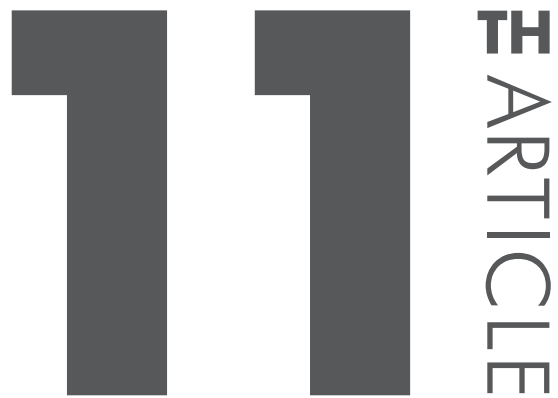

\title{
CORROSION PROTECTION OF AA-7075 ALUMINUM ALLOY SURFACE BY POLY (O-METHOXYANILINE)
}

Sandra R. Moraes ${ }^{1 *}$, Leandro D. Bisanha², Fábio A. Mattenhaver², Artur J. Motheo ${ }^{2}$

I State University of Paraná - Faculty of Philosophy, Sciences and Letters of União da Vitória, CP 291, 84600-000, União da Vitória, PR, Brazil

${ }^{2}$ São Carlos Institute of Chemistry, University of São Paulo - CP 780, 13560-970

São Carlos, SP, Brazil

\section{ABSTRACT}

This work analyzes the corrosion protection of the aluminum alloy AA7075-T6 by poly-o-methoxyaniline (POMA) films, deposited by casting solution. The potentiodynamic polarization curves obtained in $0.6 \mathrm{~mol} \mathrm{~L}^{-1} \mathrm{NaCl}$ solution indicate protective characteristics of POMA compared to polyaniline (PAni), indicating superior barrier properties. Open circuit potential measurements in $\mathrm{NaCl}$ solution and salt spray tests also confirm the efficiency of POMA films in the protection of alloy. POMA films demonstrate appreciable corrosion resistance during the exposition in salt spray, protecting the metallic surface for up to $200 \mathrm{~h}$. 
Keywords: poly(o-methoxyaniline), polyaniline, corrosion, aluminum alloy, AA-7075-T6

*Corresponding author. phone: +55 16273 9932; fax: +55 16273 9952;

e-mail: sandraremo@yahoo.com.br and artur@iqsc.sc.usp.br

\section{INTRODUCTION}

Studies of the electrochemical behavior of aluminum alloys in aqueous solutions of $\mathrm{NaCl}$ reveal that these alloys, when exposed to chloride ions, present localized corrosion, usually denoted as pitting corrosion [1,2]. Aluminum alloys corrode depending on their composition, for example copper in the alloy increases pitting attack by forming galvanic couples. Since an alloy has simultaneously anodic and cathodic sites in constant electrical contact, the best way to inhibit corrosion is to interrupt this contact. There are many methods to prevent corrosion and the most commonly used includes organic or inorganic barrier coatings and passivating inhibitors, such as conducting polymers. Complete protection can often be obtained by combining a cathodic or anodic inhibitor with a barrier coating [3].

The AA-7075 aluminum alloy has been extensively investigated due to its broad application in the aerospace industry. This alloy presents a heterogeneous and complex microstructure, composed of primary alloying elements, such as, coopper, zinc, magnesium and iron in solid solution and, forming zones, precipitates and intermetallic particles of various shapes, sizes and compositions $[3,4]$.

Initial studies concerning the corrosion protection of mild and stainless steels began by using polyaniline (PAni) and polypyrrole (PPy) [5-7]. In the course of investigating the corrosion protection of mild and stainless steels, PAni has achieved its preferential position and interest due to its straightforward polymerization, excellent chemical stability, and high conductivity. Subsequently, a number of papers have been published on corrosion protection of steels by PAni films [8-13].

In others studies, soluble polyanilines such as poly(o-methoxyaniline) (POMA) [14] and poly (o-ethoxyaniline) [15] have been considered for use as organic inhibitors against corrosion and for reduction of the corrosion rate of iron in $\mathrm{HCl}$ solution. The use of substituted polyaniline prepared by chemical oxidation has also been investigated and POMA, also called as poly(anisidine), has shown to be efficient as inhibitor against corrosion. This has been attributed to the formation of complexes with metallic surface, such as stainless steel [16], copper [17,18] and carbon steel [19].

Shah et al. [20] electropolymerized POMA by cyclic voltammetry on the aluminum alloy AA-2024 from $0.3 \mathrm{~mol} \mathrm{~L}^{-1}$ oxalic acid solution containing 0.1 
mol L-1 o-methoxyaniline and evaluated the corrosion protection promoted by POMA coatings by potentiodynamic polarization. The authors reported that POMA coatings stabilize the passive films on the AA-2024 alloy reducing the metal dissolution. Additionally, this helps to ennoble the metal surface, but do not reduce the corrosion rate of metal.

Recent investigations report that effective corrosion protection can be obtained by the undoped or non-conducting form of PAni. The protection is not only by barrier effect, but it is believed that conducting polymers contribute to the formation of a passive oxide layer on the steel surface through metal its oxidation [21].

Actually, PAni has been categorized as an intractable polymer for being neither dissolved in conventional organic solvents used in the painting industry and nor can be applied after melting. However, PAni is easily electrodeposited at inert electrodes such as gold and platinum, but it is much more difficult to generate this polymer at aluminum electrodes. This is related to the thin, but highly stable protective oxide, $\mathrm{Al}_{2} \mathrm{O}_{3}$, which forms on aluminum surface and acts as a barrier, inhibiting the electron transfer and the polymerization process. Thus, in some cases the deposition of PAni by casting solution is the more viable method, in some cases. Despite this, fewer reports describe the deposition of polyanilines (PAni and POMA) on aluminum alloys, such as AA-7075-T6 [22-26].

When other active metals are on the surface of the aluminum alloy, i.e. coopper, allied to PAni protection mechanism, others processes can occur, such as, oxidation of copper, complexation of aluminum and/or copper cations by the PAni [27] and the involvement of dissolved oxygen [12].

The aim of the present work is to present the results of corrosion protection obtained by casting solution deposition of PAni and POMA films on AA-7075-T6. To the best of our knowledge there are no studies in the literature detailing the deposition of POMA compared to PAni on AA-7075-T6, and their subsequent corrosion protection effect. So, the studies were performed by using potentiodynamic polarization curves, open circuit measurements in $\mathrm{NaCl}$ aqueous solution and salt spray tests (accelerated corrosion).

\section{EXPERIMENTAL}

\subsection{Chemicals}

Aniline and o-methoxyaniline monomers (chemical structures in Figure 1), reagent grade from Mallinckrodt, were previously vacuum-distilled over zinc dust and stored in the darkness container prior to use. All others reagents were used as received and the aqueous solutions were prepared by using Milli-Q (Millipore) water. 


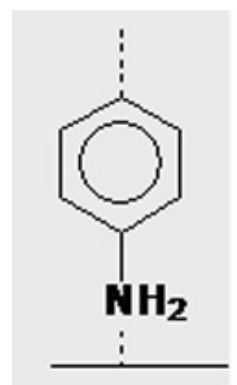

(a)

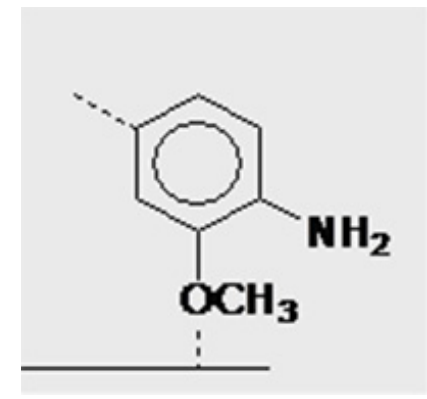

(b)

Figure 1. Chemical structure of (a) aniline and (b) o-methoxyaniline.

\subsection{Chemical polymerization of polyaniline and poly(methoxyaniline)}

The chemical syntheses of PAni and POMA were performed at $0^{\circ} \mathrm{C}$ as described by Manohar et al. [28], using a sulphuric solution $\left(0.5 \mathrm{~mol} \mathrm{~L}^{-1}\right)$ containing the monomer $\left(0.1 \mathrm{~mol} \mathrm{~L}^{-1}\right)$ and $0.1 \mathrm{~mol} \mathrm{~L}^{-1}$ ammonium peroxydisulphate $\left(\mathrm{NH}_{4}\right)$ $\left.{ }_{2} \mathrm{~S}_{2} \mathrm{O}_{8}\right)$ solution as oxidant. Open circuit potential $\left(\mathrm{E}_{\mathrm{OCP}}\right)$ and reaction temperature variations were recorded during each experiment to follow the polymer formation. The $\left(\mathrm{NH}_{4}\right)_{2} \mathrm{~S}_{2} \mathrm{O}_{8}$ aqueous solution was introduced drop-wise to the sulphuric acid solution containing the monomer and the mixture was mechanically stirred. The polymer precipitate was recovered by filtration and washed with distillated water. A part of the resulting polymer was placed in contact with $0.1 \mathrm{M} \mathrm{NH}_{4} \mathrm{OH}$ solution for $24 \mathrm{~h}$ to achieve deprotonation and then rinsed with water. Finally, the polymer was dried at $60{ }^{\circ} \mathrm{C}$ for $72 \mathrm{~h}$ under a dynamic vacuum.

\subsection{Polymers-characterization}

FTIR spectra of PAni and POMA undoped samples were obtained using a Bomem MB-102 FTIR spectrophotometer and $\mathrm{KBr}$ disc technique, in the range of $400-4000 \mathrm{~cm}^{-1}$.

\subsection{Preparation of PAni and POMA films}

The polymers in form of emeraldine base (EB) were dissolved in a solution in weight of N-methyl-2-pyrrolidone (7\% - NMP). The solution was filtered, applied on the surface by casting and dried in an oven at $45^{\circ} \mathrm{C}$ over $12 \mathrm{~h}$. The adhesion of the films on the aluminum coupons was verified by the Sellotape test. The test consists of applying pressure to the tape with pressure over the entire surface area of the sample. The tape is then removed by slow peeling back of the tape, according to the standard method (NBR 11003 [29]). The remaining underlying surface of the coating after each removal was characterized by good adhesion. 


\subsection{Preparation of electrodes}

The aluminum alloy 7075-T6 has the following nominal composition: $0.4 \%$ $\mathrm{Si}, 0.5 \% \mathrm{Fe},(2.1-2.9) \% \mathrm{Mg}, 0.3 \% \mathrm{Mn},(1.2-2.0) \% \mathrm{Cu},(0.18-0.28) \% \mathrm{Cr},(5.1-$ $6.1) \% \mathrm{Zn}, 0.2 \% \mathrm{Ti}, 0.15 \%$ other constituents and the remaining percentage as $\mathrm{Al}$ (according to ASTM-specification). AA-7075-T6 aluminum alloy plates with surface area of $(2 \times 2.5 \mathrm{~cm})$. After mechanically polishing with emery paper $(320$ to 1200 grade) and degreasing with ethanol, the samples were dried at $25^{\circ} \mathrm{C}$ and used as working electrodes

\subsection{Potentiodynamic polarization}

Using duplicate samples of each preparation, the corrosion studies were performed by obtaining potentiodynamic polarization curves at $1 \mathrm{mV} \mathrm{s}^{-1}$ in $0.6 \mathrm{M}$ $\mathrm{NaCl}$ aqueous solution at $25^{\circ} \mathrm{C}$. A single compartment electrochemical cell was used, with a plaque of the alloy with geometric area of $0.3 \mathrm{~cm}^{2}$ as the working electrode, a platinum plaque $\left(4 \mathrm{~cm}^{2}\right)$ as counter electrode and as reference, a saturated calomel electrode (SCE). A potentiostat/galvanostat 273A controlled by M352 corrosion software (EG\&G / PARC) was utilized.

\subsection{Salt Spray Test}

Three samples of each alloy without and with recovery PAni and POMA films were subjected to the salt spray test according to ASTM-B117. The surface of the aluminum alloy plates $(2 \mathrm{~cm} \times 2.5 \mathrm{~cm})$ was recovered by drop casting with PAni and POMA films. The back and edges of the substrates were isolated with alquilic resin. The samples were placed in a spray chamber (BASS, Model BASS USC- 01/02/03/-280 L) and continuously sprayed with $5 \% \mathrm{NaCl}$ solution (pH 7 ) at $35^{\circ} \mathrm{C}$. At certain times the samples were removed and visually assessed for under-film corrosion, blistering and degree of rusting.

\section{RESULTS AND DISCUSSION}

\subsection{FTIR spectrum of PAni and POMA}

Figure 2 illustrates FTIR spectra of undoped polymers. The characteristic POMA bands in the spectra occur at 2850,1600, 1210 and $1130 \mathrm{~cm}^{-1}$, in agreement with the literature $[30,31]$. At $3263 \mathrm{~cm}^{-1}$ the band is attributed to $\mathrm{N}-\mathrm{H}$ stretching vibration of the secondary amine. Due to the presence of $\mathrm{CH}_{3}$ in the POMA structure, vibration modes associated to aromatic and aliphatic C-H stretching are observed between 2933 - 2839. The bands at 1512 and $1591 \mathrm{~cm}^{-1}$ are due to benzenoid (B) and quinoid (Q) groups, respectively. The vibration modes corresponding to $\mathrm{N}-\mathrm{H}$ groups are observed at $1337 \mathrm{~cm}^{-1}$. The bands at 
1211, 1171 and $1124 \mathrm{~cm}^{-1}$ are attributed to 1,2,4 tri-substituted benzene rings in the structure [31]. Comparatively, the POMA spectrum slightly differs from the PAni one, in agreement with the literature [31].

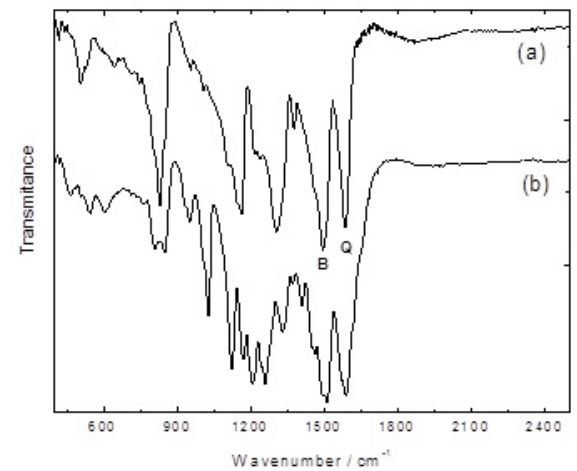

Figure 2. FTIR spectrum of (a) PAni and (b) POMA in undoped forms.

The ratio between the bands associated with benzenoid and quinoid groups (B/Q ratio) has been associated with conducting polymer conductivity [31, 33] and the amount of repetitive units that compose the polymeric chain [34]. For this association when the $\mathrm{B} / \mathrm{Q}$ ratio is 1 , the polymeric chain contains the same amount of benzenoid units and quinoid units (i.e.: 1:1). The values of the B/Q ratio obtained for PAni and POMA were approximately 0.5 and 0.97 , respectively indicating that (i) POMA presents more quinoid structures that help to increase the number of anchoring points at the surface, facilitating stronger adsorption on the aluminum alloy, and (ii) greater coverage of the surface aluminum alloy will probably enhance corrosion inhibition.

\subsection{Analysis of polymer coatings on AA-7075-T6 surface}

Polymer coatings on the AA-7075-T6 surface revealed that the nature of the monomer does not influence the film formation, as can be seen from the optical images in Fig.3. 


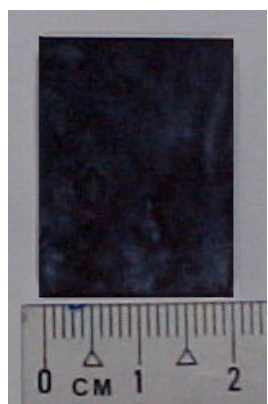

PAni

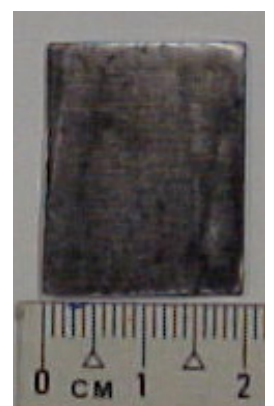

POMA

Figure 3. Optical images of AA-7075-T6 aluminum alloy after the surface to be coated with (a) PAni and (b) POMA films.

The PAni or POMA coating appear as uniform and homogeneous films on the AA-7075-T6 alloy surface (Fig.3). The film adhesion on the alloy surface was sufficiently strong that it was not possible to remove after a scratching procedure [29].

\subsection{Potentiodynamic polarization}

Figure 4 shows the potentiodynamic polarization curves of AA-7075-T6 alloy uncoated and coated with PAni and POMA films in $0.6 \mathrm{~mol} \mathrm{~L}^{-1} \mathrm{NaCl}$ solution. The corresponding corrosion potentials $\left(\mathrm{E}_{\text {corr }}\right)$, corrosion currents density $\left(\mathrm{I}_{\text {corr }}\right)$ and corrosion rate (C.R.) are presented in Table 1.

Although all the coatings caused small $(<100 \mathrm{mV})$ positive shifts in the corrosion potential, when compared to uncoated aluminum alloy, the Tafel plots revealed that only the POMA coating resulted in decrease in the general corrosion rate (about 4 times lower than PAni). Both PAni and POMA films promoted an increase in the corrosion current density, when compared to the uncoated aluminum alloy, probably as a result of improved kinetics for the oxygen reduction reaction, which occurs at the polymer/electrolyte interface.

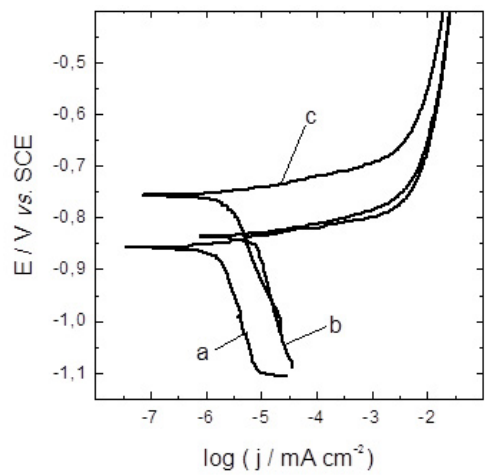

Figure 4. Potentiodynamic polarization curves of AA-7075-T6 aluminum alloy in aereated, aqueous $0.6 \mathrm{~mol} \mathrm{~L}^{-1} \mathrm{NaCl}$ solution: (a) uncoated and coated with (b) PAni and (c) POMA films. 


\begin{tabular}{|c|c|c|c|c|}
\hline Couting & $\mathbf{E}_{\text {corr }} / \mathbf{V}$ & $\mathrm{I}_{\text {corr }} / \mu \mathrm{A} \mathrm{cm}^{-2}$ & C.R. $/ \mathrm{mm} \mathrm{y}^{-1}$ & $\mathbf{E}_{\text {pit }} / \mathbf{V}$ \\
\hline No coating & -0.843 & 0.611 & 0.078 & -0.838 \\
\hline PAni & -0.836 & 7.947 & 1.019 & -0.799 \\
\hline POMA & -0.756 & 1.584 & 0.203 & -0.712 \\
\hline
\end{tabular}

Table 1. Electrochemical parameters (average values of two samples) obtained from potentiodynamic curves in aereted aqueous $0.6 \mathrm{~mol} \mathrm{~L}^{-1} \mathrm{NaCl}$ solution, for uncoated AA-7075-T6 aluminum alloy and coated by PAni and POMA films.

The above results indicate that reduced protection is promoted by PAni films and better efficiency is obtained for POMA films. This behavior can be explained by considering the greater affinity of the methoxy group in POMA structure for the metallic surface $[35,36]$. This effect results in better: (i) adsorption of POMA films on the AA-7075-T6 alloy surface and (ii) retarding of ion exchange from the electrolyte to the metal surface. These effects also were observed for Poly(o-anisidine) electrodeposited on AA-2024 [20] and PAni-POMA copolymer films on stainless steel [37].

The ineffectiveness of PAni films as corrosion inhibitors on AA-7075-T6 can be ascribed to the nature and formation of the $\mathrm{Al}_{2} \mathrm{O}_{3}$ passive layer. However, a positive shift in the corrosion potential suggests that corrosion protection occurs.

The AA-7075-T6 aluminum alloy contains high contents of copper, magnesium and zinc (inter-metallic constituting). Thus, the organic compounds on the alloy surface can act in different ways, such as by complexation of metallic ions, which are incorporated into oxide layers. In the case of organic compounds containing ionizable groups, such as the methoxy group into the POMA structure, this can electro-statically interact with the metallic surface by formation of surface complex, which can affect both the formation rate and extension of the oxide layer. Thus, POMA films are more efficient at inhibiting the corrosion process of AA-7075 in the presence of chloride ions.

\subsection{Open Circuit Potential Measurements}

Figure 5 shows the dependence of the time-open circuit potential (OCP) for AA-7075-T6 coated with PAni and POMA films, as well as for the uncoated alloy. It is evident that the AA-7075-T6 uncoated alloy presents a less negative potential compared to other systems. This is better evidenced in Fig. 5 (I), which shows the first 24 hours of immersion. When the AA-7075 alloy surface is exposed to 0.6 $\mathrm{M} \mathrm{NaCl}$ solution, the OCP is initially negative at $-1.03 \mathrm{~V}$. As expected, rapid corrosion of the metal surface occurs in this environment. In contrast, for AA-7075 coated with POMA, initially the values are more positive, climb to a steady-state value of around $-0.84 \mathrm{~V}$, while for PAni the value is around of $-0.90 \mathrm{~V}$ for a period of two-hours. 


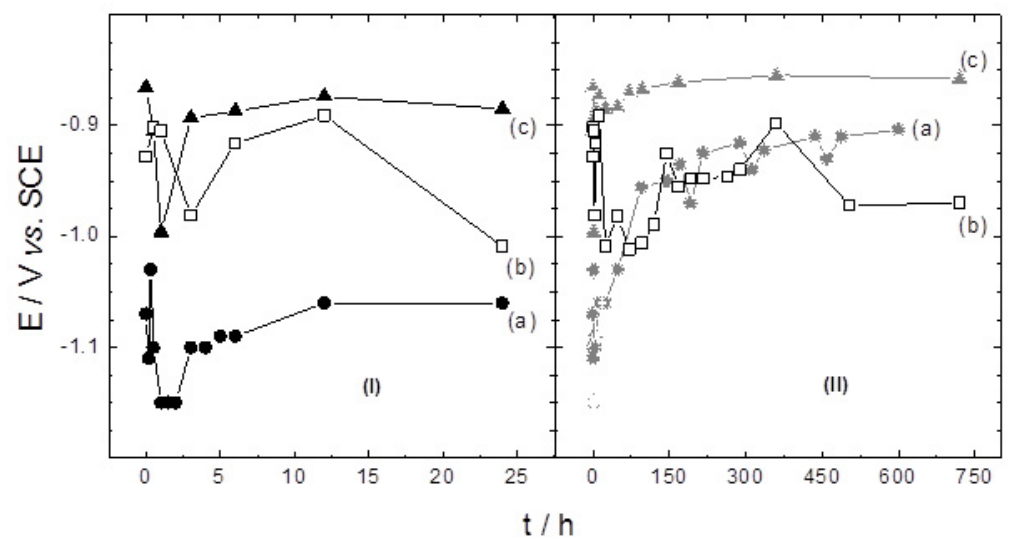

Figure 5. Open circuit potential curves of AA-7075 alloy (a) uncoated and coating with different films (b) PAni and (c) POMA in $0.6 \mathrm{~mol} \mathrm{~L}^{-1} \mathrm{NaCl}$ solution, aerated. Immersion time (I): 0 to $25 \mathrm{~h}$ and (II) 0 to $720 \mathrm{~h}$.

Over a period of $720 \mathrm{~h}$ in $\mathrm{NaCl}$ solution was not observed the delamination of the PAni and POMA films. However, POMA films, coated on AA-7075, promoted a better ennoblement of the metal surface due to passivation (Fig. 5 (II)).

Interpretation of OCP values is very complicated due to (i) the substrate is an aluminum alloy with superficial electrochemical cells which probably determines the value of the OCP [38]; (ii) the medium (aerated $\mathrm{NaCl}$ ) simultaneously contains both molecular oxygen and chloride ions; (iii) the different films on the AA-7075 surface can have anodic corrosion inhibition properties. Beyond all this, these factors allied to the redox reaction that occurs at the conducting polymers/ metal interface, can also be responsible for the oscillations in the OCP during the first hours of immersion in solution. These results substantiate earlier results as well as demonstrating that POMA films are quite effective against corrosion even when there is no top barrier coating.

\subsection{Salt Spray Test}

The salt spray test was performed on AA-7075-T6 plates uncoated and for the two coating systems (PAni and POMA films). Among properties of films were assessed the blistering by the corrosion and the degree of rusting. Figure 3 shows the optical images of different samples at initial time, while the Figure 6 shows the optical images of PAni and POMA films after $200 \mathrm{~h}$ exposition in salt spray. 


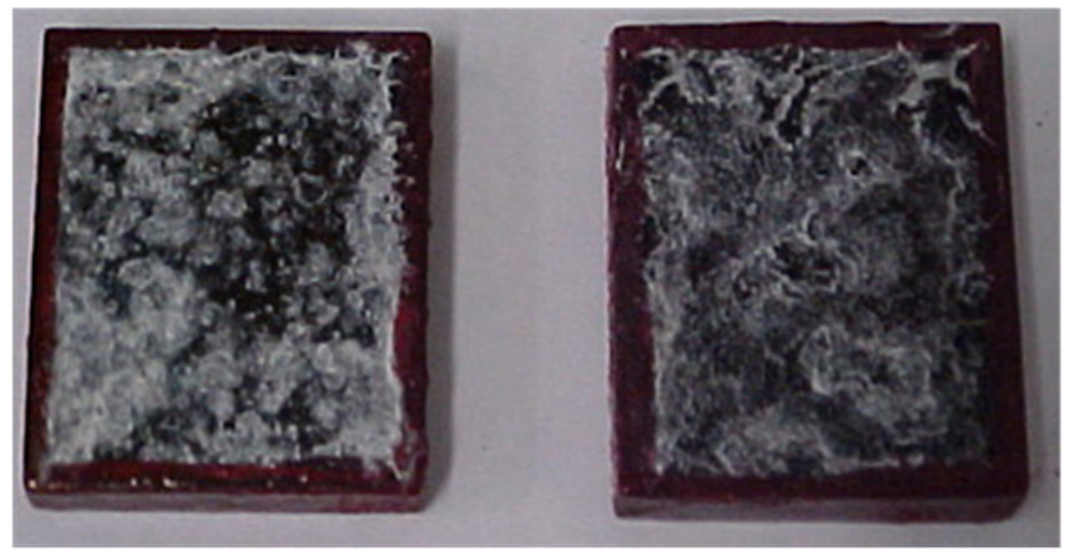

PAni

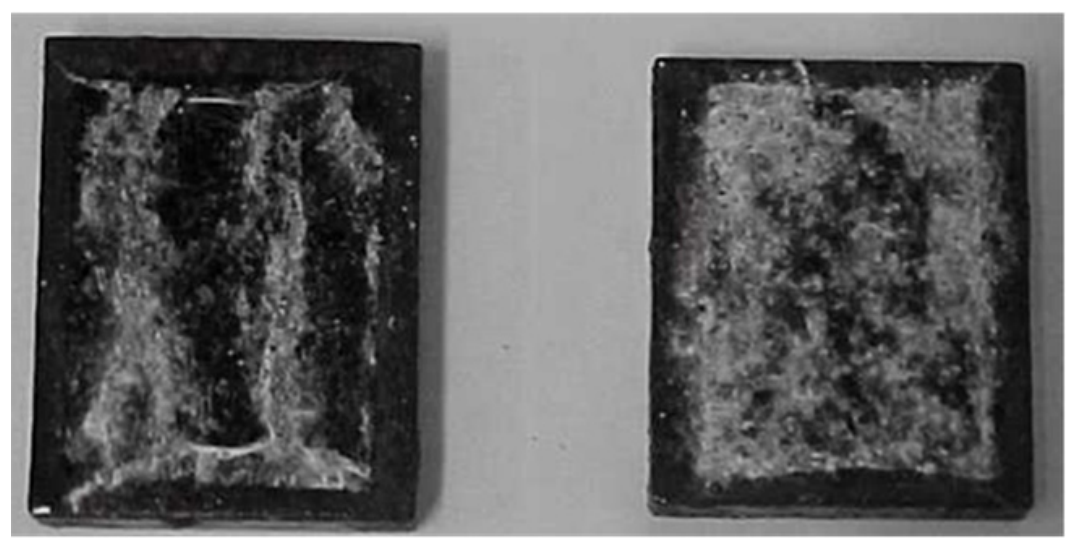

POMA

Figure 6. Optical images of AA-7075-T6 alloy plates coated with PAni and POMA films after 200 hours of exposition in salt spray test. Duplicated samples.

The test showed that both coating systems provide efficient corrosion protection and complete suppression of under film corrosion over a period of more than 144 hours. In particular, for POMA films significant change occurs between same sample and this is observed after 200 hours. This must be regarded as an indication of the efficiency of the corrosion control by POMA films. In the case of PAni films on AA-7075-T6, there was a marked tendency to form blisters and this occurs in the first 15 hours. The same occurred to POMA films, though the blistering was not observed until after 24 hours (images no showed). The results of the salt spray test strongly corroborate with prior results, making it viable for individual investigation as an organic coating system for industrial applications. 


\section{CONCLUSIONS}

Chemically synthesized POMA films protect the AA-7075-T6 aluminum alloy against corrosion in the presence chloride ions. Comparatively, POMA films are more efficient than PAni films. Potentiodynamic polarization measurements in $0.6 \mathrm{~mol} \mathrm{~L}^{-1}$ sodium chloride solution show more noble characteristics of AA7075-T6 coated with POMA films, indicative of its superior barrier properties. The barrier property contributes appreciably towards the corrosion resistance of POMA films. These films demonstrate an appreciable corrosion resistance without any top barrier coat, indicating that the adhesion strength of POMA films on the AA-7075-T6 aluminum alloy surface was found to be appreciable, and when exposed to the accelerated corrosion tests the films were less affected.

\section{ACKNOWLEDGEMENTS}

The authors wish to thank FAPESP (Contract Number 05/04641-4 and 04/12189-1) and CAPES for their financial support.

\section{REFERENCES}

[1] Z Szklarska-Smialowska, Corr. Sci. 41, 9, (1999) 1743.

[2] Z Szklarska-Smialowska, Corr. Sci. 44, 5, (2002) 1143.

[3] Comotti, IM, M Trueba, SP,Trasatti, Surf. Interface Anal., 45,10, (2013) 1575.

[4] F Andreatta, H Terryn, JHW Wit, Electrochim. Acta. 49, 17-18, (2004) 2851.

[5] P Hidalgo-Manrique, CM Cepeda-Jimenez, A Orozco-Caballero, OA Ruano, F Carreno. J Mater Sci, 49, (2014) 833.

[6] S Sathiyanarayanan, SK Dhawan, DC, Trivedi, K. Balakrishnan, Corros. Sci. 33, 12, (1992), 1831.

[7] WK, Lu, RL, Elsenbaumer, B Wessling, Synth. Met. 71, 1-3, (1995) 2163.

[8] BD Mert, B Yazici, SB Lyon, Corros. Eng., Sci. Technol., 48, 7, (2013), 506.

[9] M Fahlman, S Jasty, AJ Epstein, Synth. Met. 85, 1-3, (1997) 1323.

[10] JR Santos Junior, LHC Mattoso, AJ Motheo, Electrochim. Acta, 43, 3-4, (1998) 309.

[11] DE Tallman., Pae Y, Bierwagen G.P. Corrosion, 55, 8, (1999) 779.

[12] PJ Kinlen, DC Silverman., CR. Jeffers, Met. 85, 1-3, (1997) 1327.

[13] S Chaudhari, AB Gaikwad, PP Patil, Curr. Appl. Phys., 9, 1, (2009) 206.

[14] SK Dhawan., DC Trivedi, J. Appl. Polym. Sci., 58, 4, (1995) 815

[15] R Vera, H Romero, YE Ahumada, J. Chil. Chem. Soc., 48, 1, (2003) 35. 
[16] PA Kilmartin, L Trier, GA Wright, Synth. Met., 131, 1-3, (2002) 99.

[17] S Chaudhari, AB Mandale, KR Patil, SR Sainkar, PP Patil, Surf. Coat. Technol. 200, 18-19, (2006) 5557.

[18] S Chaudhari, KR Sainkar, PP Patil. J, Phys. D. Appl. Phys. 40, 2, (2007) 520.

[19] MG Wankhede, SA Gangal, PP Patil, Corros. Eng., Sci. Technol. 40, 2, (2005) 121.

[20] K Shah, J Iroh, Adv. Polym. Techn, 23, 4, (2004) 291.

[21] RL Twite, GP Bierwagen, Prog. Org. Coat., 33, 2, (1998) 91.

[22] D Huerta-Vilca,. SR Moraes, AJ Motheo, J. Solid State Electrochem. 9, 6, (2005) 416.

[23] D Huerta-Vilca,. SR Moraes, AJ Motheo, Synth. Met. 140, 1, (2004) 23.

[24] D Huerta-Vilca, SR Moraes, AJ Motheo, J. Appl. Electrochem. 33, 5, (2003) 355.

[25] D Huerta-Vilca, SR., Moraes, AJ Motheo, J. Appl. Polymer Sci. 90, 3, (2003) 819.

[26] D Huerta-Vilca, SR Moraes, AJ Motheo,. J. Braz. Chem. Soc. 14, 1, (2003) 52.

[27] AJ Epstein, JAO Smallfield, H Guam, M Fahlman, Synth. Met. 102, 1-3, (1999) 1374.

[28] SK Manohar, AG MacDiarmid, Synth. Met. 41, 1-2, (1991) 711.

[29] ABNT Tintas. Determinação de aderência NBR 11003. ABNT (1990), Rio de Janeiro

[30] XG Li, LX, Wang, MR Huang, YQ Lu, MF Zhu, A Menner, Springer, J. Polymer, June, 42, 14, (2001) 6095.

[31] MJ Rahman, AH Bhuiyan, Thin Solid Films, 534, (2013) 132.

[32] J Tang, X Jing, B Wang, F Wang, Infrared spectra of soluble polyaniline. Synth. Met. 24, 3, (1988) 231.

[33] AJ Motheo, MF Pantoja, EC. Venancio, Solid State Ionics, 171, 1-2, (2004) 91.

[34] HS Nalwa, Handbook of organic conductive Molecules and Polymers, vols.14, New York, Wiley, (1997).

[35] A Sankar, V Ragunathan, K Mohankumar, Asian J. Chem., 23, 6 (2011) 2673.

[36] X Wang, S Ray, M Gizdavic-Nikolaidis, AJ Easteal, J. Polym. Sci., Part A: Polym. Chem., 50, 2 (2012) 353.

[37] D Huerta-Vilca,. B Siefert, SR Moraes, MF Pantoja, AJ Motheo, Mol. Cryst. Liq. Cryst. 415, (2004) 387.

[38] GO Ilevbare, JR Scully, J Yuan, RG. Kelly, Corrosion, 56, 3, (2000) 227. 